\title{
Integration of the Web into an Engineering Economy Course
}

\author{
William N. Smyer \\ Mississippi State University
}

\begin{abstract}
This paper presents a summary of a project to integrate the World Wide Web into an undergraduate engineering economy course. The thrust of the paper is a discussion of the experiences gained by the students and a faculty member who is a web-authoring novice.

Perhaps the most significant web additions are a set of lecture outlines and a set of interactive tutorials. The lecture outlines are approximately $80 \%$ complete notes. Thus the student notetaking burden is significantly reduced compared to not having the lecture outlines. Providing incomplete notes creates an incentive for students to attend class to complete their notes.

The interactive tutorials consist of topic discussions followed by multiple-choice questions. An incorrect response leads to a page that gives a brief comment about why the response may be incorrect, thus providing an additional learning experience.

Case studies, answers to selected text questions, and other items are also web-based.

Sample web pages are displayed. Student evaluations of the course before and after web integration are presented, and areas for further improvement are explored.

\section{Introduction}

This paper presents an overview of a project to integrate the use of the World Wide Web into an undergraduate engineering economy course. A continuous improvement approach is taken, with changes implemented based on student feedback each semester.

\section{The Fall 1998 Course}

At Mississippi State, the three-hour undergraduate course in engineering economy is conducted during the academic year by delivering a 50-minute lecture two days per week with an average enrollment of 180 in the fall and 120 in the spring, plus several 50-minute laboratory/recitation sections one day per week with an average enrollment of 30 students per section. Each student enrolls in the single, large lecture section plus one of the laboratory sections, the latter conducted by graduate assistants. The laboratory sessions consist of homework submission, quizzes, working example problems and answering student questions.
\end{abstract}


In the fall 1998 semester, the large lecture classes were conducted by using pre-printed overhead transparencies. Course handouts were hard copy and distributed either in the large lecture or in a laboratory period. Students took notes in the traditional manner during the lectures, and had the usual difficulty of attempting to take notes and listen to the instructor simultaneously. Numerous students expressed frustration over this difficulty and the comments were justified. The author, who had not taught for several years, failed to adjust adequately to the fact that the use of preprinted overhead transparencies significantly increases the pace of a lecture compared to a traditional "chalk and board" lecture.

The fall 1998 final grade distribution for students who completed the course is given in Table 1 .

Table 1. Fall 1998 Final Grade Distribution.

\begin{tabular}{|r|c|c|c|c|c|c|}
\hline Grade & A & B & C & D & F & ALL \\
\hline Frequency & 43 & 44 & 32 & 16 & 15 & $\mathbf{1 5 0}$ \\
\hline
\end{tabular}

This distribution results in an average class grade point average (GPA) of 2.56 on a 4.0 scale.

III. Course Changes for the Spring 1999 Semester

The most important change for spring 1999 was to provide an environment in which students could both take adequate notes and reflect on the class discussion. In the auditorium setting required for such a large class, the use of a chalkboard was not viable even if desired.

One action considered was to sell to the student a complete set of lecture notes at the start of the semester. Providing complete notes, however, would reduce the student's incentive to attend the lectures (attendance is optional) and benefit from class discussions and questions. Providing complete notes on the web suffered the same weakness. Requiring attendance at the lectures by having absences affect the final grade was considered but rejected. A method of positive reinforcement of attendance at the lectures was desired.

Providing students with partially completed notes would reduce the note-taking burden while maintaining an incentive for students to attend class to complete their notes. As Paterson ${ }^{1}$ says in his paper, "... partial notes allowed students to remain engaged during class." This "fill in the blank" plan was adopted for the spring 1999 semester, with the partially completed notes denoted "Lecture Outlines." An arbitrary target of $80 \%$ complete was adopted for the lecture outlines. That is, the student would need to attend the lectures to obtain the remaining $20 \%$ or so of lecture material.

Two methods of lecture outline distribution were considered: hard copy and web. The web was selected and that decision proved to be popular with the students, as will be seen later in the results of a survey. 
A web site was created, and the Lecture Outlines, case studies, answers to selected text questions, homework assignments, old tests, and other items were uploaded to the site for the spring 1999 semester.

\section{Web Page Authoring}

Time was limited between the end of the fall semester and the start of the spring. With no knowledge of HTML [Hyper-Text Markup Language] and no experience in web page creation, the author used a word processing application, Microsoft Word, to create web pages quickly. Little regard was given to web page aesthetics, and the course web pages remain simple but functional.

The ability to save documents in HTML format is now a common feature in word processing software such as Word and WordPerfect. However, a web page authoring specific tool such as Microsoft FrontPage offers more features and can also be used with no knowledge of HTML, if needed. FrontPage 2000 is now being used to maintain the engineering economy web site.

The web server used in the spring 1999 term was a Sun machine, running a Unix-based operating system, while the PC used to create web pages runs on a Microsoft operating system [Windows@ 98]. Thus, an FTP utility was needed to transfer files between the two machines. (Now both the primary and secondary servers are Windows $@$ NT $@$ machines, which allows web pages to be saved directly to the servers from the authoring software.)

A portion of a lecture outline is shown in Figure 1.

Figure 1. Sample Lecture Outline

\section{IE 3913 Engineering Economy I}

\section{Depreciation and Depletion}

is a decrease in value of an asset, not a

Notation:

$=$ initial cost of asset = estimated asset salvage value $=$ estimated service life $=$ depreciation charge EOY $t, t=1,2, \ldots, n$ $=$ asset book value EOY $t, t=1,2, \ldots, n$

$\mathrm{B}_{\mathrm{t}}=\mathrm{P}-($ accumulated depreciation through year $\mathrm{t})=$ 
During the lecture, the student is expected to write the words "Depreciation" and "cash flow" in the first sentence of the example to complete that sentence.

Many students own computers, so access to the web-based lecture outlines for those students is not a problem. Other students have access to departmental computer laboratories as well as two "public" computer laboratories that are open approximately eighteen hours per day. Black and white printing in the computer laboratories is provided to the student at no cost. Color printing is available at a cost of $\$ 0.50$ per page. (College of Engineering student ownership or lease of a computer is required beginning with the fall 1999 semester.)

\title{
V. The Spring 1999 Course
}

In addition to the lecture outlines, complementary materials were added both prior to and during the spring 1999 semester, primarily at the suggestion of students. The main menu for the spring 1999 semester is shown in Figure 2, with graphic images, external links and required university boilerplate removed from this paper for clarity and to reduce file size. The complete web page can be viewed at the URL http://www2.ie.msstate.edu/courses/engr_econ/index.html. As of this writing, the course web site is not password protected. If it later becomes so, the login and password may be obtained from the author at smyer@ie.msstate.edu .

Figure 2. Spring 1999 Main Menu

\section{IE 3913 Engineering Economy I}

\author{
Course Resources
}

Answers to Recommended Text Problems

Case Studies

Course Information: Grade Weighting, Testing, etc.

Course Syllabus: Topics and Test Dates

Homework

Lecture Outlines

Previous Tests and Solutions

Test Outlines

A formal, university-wide student evaluation of teaching program is conducted near the end of the fall and spring semesters by the Office of Planning, Evaluation and Institutional Effectiveness, with the results returned to the instructor shortly after the start of the next semester. The survey is conducted without instructor involvement. 
Effective with the spring 1999 semester, an informal student survey is administered by the instructor in the engineering economy course late in the semester, with immediate feedback to the instructor. Furthermore, the results of the survey are shared with the class at the next lecture.

The results of the spring 1999 informal survey showed that the web integration was a positive change, although further improvements were indicated as detailed in Table 2.

Table 2. Spring 1999 Informal Student Survey (only web-oriented questions shown)

\begin{tabular}{|c|c|c|}
\hline & Yes & No \\
\hline \multirow{2}{*}{$\begin{array}{l}\text { Do you use the web-based lecture outlines to take notes in class? } \\
\text { If No, why not? }\end{array}$} & $88.6 \%$ & $11.4 \%$ \\
\hline & \multicolumn{2}{|c|}{$\begin{array}{l}\text { No web access (1) } \\
\text { I forget to print them (1) }\end{array}$} \\
\hline \multicolumn{3}{|l|}{ The web-based materials are: } \\
\hline useful; continue doing this & \multirow{6}{*}{\multicolumn{2}{|c|}{$\begin{array}{l}95.0 \% \\
0.0 \% \\
5.0 \%\end{array}$}} \\
\hline not useful; discontinue & & \\
\hline fair, with the improvements below needed: & & \\
\hline Make sure everyone has web access (1) & & \\
\hline Vary fonts to distinguish between sections (1) & & \\
\hline Try to fit more on each web page (1) & & \\
\hline \multicolumn{3}{|l|}{ Other comments, if any, on the use of the web in this course: } \\
\hline \multicolumn{3}{|l|}{ Positive comments (19) } \\
\hline \multicolumn{3}{|l|}{ Improve formatting of web pages - too much wasted space (4) } \\
\hline \multicolumn{3}{|l|}{ Provide full solutions to problems on web, not just answers (2) } \\
\hline \multicolumn{3}{|l|}{ Sometimes getting web access is hard to do (1) } \\
\hline \multicolumn{3}{|l|}{ Occasional printing problems with special characters (1) } \\
\hline \multicolumn{3}{|l|}{ Don't rely too heavily on web to assign homework (1) } \\
\hline Tell students to print all web materials at start of semester (1) & & \\
\hline
\end{tabular}

The formal student evaluations of teaching results for the spring 1999 semester lectures showed a marked improvement from the fall 1998 semester. In this survey, a series of ten statements is presented to the student with five possible responses per statement, as follows:

$1=$ strongly disagree $2=$ disagree $\quad 3=$ neutral $\quad 4=$ agree $\quad 5=$ strongly agree .

The ten statements in the survey are:

The instructor makes the material interesting and holds the attention of the class.

The instructor makes the material relevant to my course of study.

The instructor communicates clearly.

Presentations by the instructor are well organized. 
The instructor knows if the course content is being understood.

The instructor is reasonably accessible to students out of class.

I have had to work hard in this course.

I have become more competent in this area because of this instructor.

Grading and evaluation procedures by the instructor seem fair and objective.

If I take another course in this subject, I would like to have this instructor.

The College of Engineering overall average response for the questions is typically about 4.00. The fall 98 engineering economy class overall average response for the statements was below both the departmental average and College of Engineering average. The spring 99 class overall average response for all ten questions was above the departmental average and well above the college average. The increase from fall to spring in average response per statement ranged from -0.01 (a decrease) to +0.95 , with an average increase per statement of +0.47 . A paired-sample $t$ test shows that the mean increase is significant at the $1 \%$ level of significance $(t=5.11)$.

Table 3 gives the spring 1999 final grade distribution for students who completed the course.

Table 3. Spring 1999 Final Grade Distribution

\begin{tabular}{|r|c|c|c|c|c|c|}
\hline Grade & A & B & C & D & F & ALL \\
\hline Frequency & 45 & 35 & 16 & 9 & 9 & 114 \\
\hline
\end{tabular}

This distribution results in an average class GPA of 2.86, a 0.30-point increase from fall 1998.

Despite the positive student responses concerning web integration and the improvement of final grades from fall to spring, it is not possible to conclude with any degree of statistical confidence that the web integration had a significant effect on the final grade distribution. This inability is due to other factors confounding the experiment such as the spring 1999 students having access to the three fall 1998 major tests.

VI. Changes for the Fall 1999 Semester

The lecture outlines were revised to correct errors, improve formatting, and recreate special characters such as $\triangle \mathrm{ROR}$ using a character set more web-compatible than that used initially. The problem of printing special characters was alleviated but not eliminated. It was learned that the problem is sometimes browser and/or printer dependent.

A link to demonstrate the use of Excel spreadsheet software to find an internal rate of return of a net cash flow was added to the main menu.

Creation of a backup web site was accomplished for the fall 1999 semester. 
Based on suggestions from students enrolled in the spring 1999 class, a set of interactive tutorials was developed and uploaded during the summer for use beginning fall 1999. An estimated 80 hours of effort by the instructor were required to develop and test the tutorials.

VII. The Interactive Tutorials

The interactive tutorials consist of topic discussions followed by multiple-choice questions. An incorrect response takes the student to a page that gives a brief comment about why the response may be incorrect, thus providing an additional learning experience.

Clicking on "Interactive Tutorials" on the main menu produces another menu consisting of one link for each of the "fundamentals" chapters. Currently this menu appears as shown in Figure 3.

Figure 3. Tutorials Menu

\section{IE 3913 Engineering Economy I}

\section{Interactive Tutorials}

Chapter 3 - Interest and Equivalence

Chapter 4 - More Interest Formulas

Chapter 5 - Present Worth Analysis

Chapter 6 - Annual Cash Flow Analysis

Chapters 7 and 8 - Rate of Return Analysis

The chapter numbers and titles are taken from Newnan and Lavelle ${ }^{2}$, the current course text.

Clicking on a chapter will produce a chapter tutorial menu. For example, clicking on Chapter 3 Interest and Equivalence results in the menu shown in Figure 4.

Figure 4. Chapter 3 Tutorials Menu

\section{Chapter 3. Interest and Equivalence}

3A. Single payment compound interest formulas (annual)

3B. Single payment compound interest formulas (other periods)

3C. Single payment simple interest formulas (annual)

3D. Single payment compound interest (solving for $\mathrm{i}$ or $\mathrm{n}$ )

\section{$\underline{\text { Return to Tutorials menu }}$}

If the user then selects, for example, item "3A. Single payment compound interest formulas (annual)," the page shown in Figure 5 appears. 
Figure 5. Topic 3A Tutorials Menu

\section{Chapter 3. Interest and Equivalence}

\section{A. Single payment compound interest formulas (annual)}

\section{Go to questions covering topic below}

Given a present dollar amount $\mathrm{P}$, interest rate i\% per year, compounded annually, and a future amount $F$ that occurs $n$ years after the present, then the relationship between these terms is: $F=P(1+i)^{n}$. In equations, the interest rate i must be in decimal form, not percent. Example: If $\$ 100$ is invested at $6 \%$ interest per year, compounded annually, then the future value of this investment after four years is:

$F=P(1+i)^{n}=\$ 100(1+0.06)^{4}=\$ 100(1.06)^{4}=\$ 100(1.262)=\$ 126.20$

Solving the above equation for $P$ yields: $P=F(1+i)^{-n}$

The factors $\mathrm{F} / \mathrm{P}$ and $\mathrm{P} / \mathrm{F}$ are available in interest tables, simplifying somewhat the calculations. $(F / P, i \%, n)=(1+i)^{n}(P / F, i \%, n)=(1+i)^{-n}$

Given a present dollar amount $\mathrm{P}$, interest rate i\% per year, compounded annually, and a future amount $F$ that occurs $n$ years after the present, then the relationship between these terms is: $F=P(1+i)^{n}$. In equations, the interest rate i must be in decimal form, not percent. Example: If $\$ 100$ is invested at $6 \%$ interest per year, compounded annually, then the future value of this investment after four years is:

$F=P(1+i)^{n}=\$ 100(1+0.06)^{4}=\$ 100(1.06)^{4}=\$ 100(1.262)=\$ 126.20$

Solving the above equation for $P$ yields: $P=F(1+i)^{-n}$

The factors F/P and P/F are available in interest tables, simplifying somewhat the calculations.

$(F / P, i \%, n)=(1+i)^{n}$

$(P / F, i \%, n)=(1+i)^{-n}$

After viewing the tutorial material on topic $3 \mathrm{~A}$, for example, the user may proceed to questions on this topic by clicking on the link: Go to questions covering topic below, which produces the web page shown in Figure 6. 
Figure 6. Topic 3A Questions Menu

\section{Chapter 3. Interest and Equivalence}

3A. Single payment compound interest formulas (annual)

Question 3A1

Question 3A2

Question 3A3

Question 3A4

Return to Topic 3A

Return to Chapter 3 Tutorials Menu

Return to Tutorials Menu

Return to IE 3913 Menu

Each tutorial question is multiple choice with four possible responses per question.

If the user next clicks on Question 3A1, the web page shown in Figure 7 appears.

Figure 7. Question 3A1

\section{Question 3A1.}

Suppose that $\$ 1,000$ is invested for six years at an interest rate of $10 \%$ per year, compounded annually. How much will be in the account at the end of six years? Choose an answer by clicking on one of the letters below, or click on "Review topic" if needed.

$\underline{\mathbf{A}}: \mathrm{F}=\$ 1,000+\$ 600=\$ 1,600$

B: $F=\$ 1,000(1.06)^{10}=\$ 1,791$

C: $F=\$ 1,000(1.10)^{6}=\$ 1,772$

$\underline{\text { D: }} \mathbf{F}=\$ 1,000(1.06)^{-10}=\$ 558$

\section{Review topic}


The correct answer is "C." If the user clicks on C, the page shown in Figure 8 is displayed.

Figure 8. Correct Response C to Question 3A1

Your response is correct.

Choose an option below.

Return to current question

Move to next question

Return to Chapter 3 Tutorials menu

Return to Tutorials menu

Return to IE 3913 menu

If the user selects incorrect response A, for example, the web page shown in Figure 9 appears.

Figure 9. Incorrect Response A to Question 3A1

Response is incorrect.

Your response is correct for simple interest, but not compound interest.

Click the browser Back button to try again.

Instructional comments on incorrect response pages are context-sensitive. That is, each comment takes into account how the student erred.

VIII. The Fall 1999 Course

The fall 1999 main menu, with Tutorials and Using Excel added, is shown in Figure 10. 
Figure 10. Fall 1999 Main Menu

\section{IE 3913 Engineering Economy I}

Course Resources - IE Server

Adobe Acrobat Info

Announcements and Notes

Answers to Text Problems

Case Studies

Course Information

Course Syllabus

Excel Information
Homework

Interactive Tutorials

Lab Schedules

Lecture Outlines

MSU Computer Labs

Old Tests and Solutions

$\underline{\text { Test Outlines }}$

The experiences of the fall 1999 class showed that the web integration continued to be strongly supported by the students, as indicated in Table 4 .

Occasional server outages continued to be an annoyance, but not a serious problem.

Most students who used the interactive tutorials made positive comments about them, but only about half the class ever accessed them. 
Table 4. Fall 1999 Informal Student Survey (only web-oriented questions shown)

\begin{tabular}{|c|c|c|}
\hline \multirow{3}{*}{$\begin{array}{l}\text { Do you use the web-based lecture outlines to take notes in } \\
\text { class? } \\
\qquad \text { If No, why not? (Fall 99) }\end{array}$} & Fall 99 & Spring 99 \\
\hline & $\begin{array}{l}\text { Yes: } 97.0 \% \\
\text { No: } 3.0 \%\end{array}$ & $\begin{array}{l}\text { Yes: } 88.6 \% \\
\text { No: } 11.4 \%\end{array}$ \\
\hline & \multicolumn{2}{|c|}{$\begin{array}{l}\text { Don't need them (1) } \\
\text { Don't take notes in any class (1) } \\
\text { Could not find a hole punch (1) }\end{array}$} \\
\hline $\begin{array}{l}\text { The web-based materials are: } \\
\text { useful; continue doing this } \\
\text { not useful; discontinue } \\
\text { Fall 99: } \quad \text { fair, with the improvements below needed: }\end{array}$ & $\begin{array}{l}\text { Fall } 99 \\
95.0 \% \\
0.0 \% \\
5.0 \%\end{array}$ & $\begin{array}{l}\text { Spring } 99 \\
95.0 \% \\
0.0 \% \\
5.0 \%\end{array}$ \\
\hline \multicolumn{3}{|l|}{$\begin{array}{l}\text { Don't want old tests if that means ours are harder (1) } \\
\text { Don't use them but I would say keep them (1) }\end{array}$} \\
\hline Have you used the web-based tutorials at least once? & Fall 99 & \\
\hline $\begin{array}{l}\text { Yes } \\
\text { No }\end{array}$ & $\begin{array}{l}42.4 \% \\
57.6 \%\end{array}$ & \\
\hline If you used the tutorials, what is your opinion of them? & Fall 99 & \\
\hline Useful; continue doing it and expand them & $81.0 \%$ & \\
\hline Fair, with the improvements noted below needed & $19.0 \%$ & \\
\hline Not useful & $0.0 \%$ & \\
\hline \multicolumn{3}{|l|}{ Suggestions for improvements to the tutorials (Fall 99): } \\
\hline \multicolumn{3}{|l|}{$\begin{array}{l}\text { Warn everyone that tutorials are easier than the tests (5) } \\
\text { They are good. Add more. (1) }\end{array}$} \\
\hline \multicolumn{3}{|c|}{ Other comments, if any, on the use of the web in this course (Fall 99): } \\
\hline $\begin{array}{l}\text { Positive comments (32) } \\
\text { Upload completed (no blanks) notes after class or test (4) } \\
\text { A lot of wasted space in notes (1) } \\
\text { The one time I planned to use, the server was down (1) } \\
\text { This class has made me more organized (1) } \\
\text { Besides the mistakes, the web is very helpful (1) } \\
\text { More problems and more chapters in tutorials (1) } \\
\text { More examples of homework and test questions (1) } \\
\text { Only use to print class notes (1) }\end{array}$ & & \\
\hline
\end{tabular}

The university student evaluations of teaching results are not available for the fall 1999 semester at this time, and the final grade distribution also is not yet available. 


\section{Summary and Future Plans}

An instructor who is a web-authoring novice can be effective in web integration by using a minimal set of common, simple tools. Factor confounding makes it impossible to conclude by statistical analysis that the engineering economy course at Mississippi State has been significantly improved by web integration, but both the students and instructor believe that to be the case based on surveys, final grades, and anecdotal data.

Compared to most other course web sites, the IE 3913 site is unsophisticated, which is not necessarily a negative. However, additions are planned including an on-line bulletin board, more tutorial topics and problems, and multimedia files. For example, a movie showing how net present worth changes as the interest rate changes would be of benefit to students. Two possible additions, to be evaluated carefully, are archived videos of lectures and web-based testing.

Acknowledgements

This project was supported in part by the Mississippi State University College of Engineering from a grant from the Robert M. Hearin Foundation of Jackson, Mississippi. The author gratefully acknowledges the assistance of students who provided feedback to improve the engineering economy course, and the web-authoring mentoring of Dr. David B. Kaber, Assistant Professor of Industrial Engineering at Mississippi State.

Bibliography

1. Paterson, K. G., "Student Perceptions of Internet-Based Learning Tools in Environmental Engineering Education," Journal of Engineering Education, vol. 88, no. 3, pp. 295-304 [July 1999].

2. Newnan, D. G., and J. P. Lavelle, Engineering Economic Analysis, Engineering Press, Austin, Texas, Seventh Edition, 1998.

\section{WILLIAM N. SMYER}

Bill Smyer is an Associate Professor of Industrial Engineering at Mississippi State University. He received his B.S., M.S. and Ph.D. degrees in Industrial Engineering from Auburn University. He has extensive industrial experience, both full-time and in consulting roles, and he served as Associate Dean of Engineering for Undergraduate Studies and Administration at Mississippi State for seven years before returning to full-time teaching in August 1998. 